\title{
Does the Maastricht Public Debt Criterion Call for Fiscal Expansion or Contraction?
}

\author{
Pekka Ahtiala* \\ University of Tampere
}

\begin{abstract}
The M aastricht convergence criteria of the $E$ conomic and $M$ onetary U nion of Europe stipulate that the public debt of a member country may be at most 60 per cent, and the fiscal deficit at most 3 per cent of the GNP, which has led member governments to contract their expenditures. A simple two-country flow equilibrium model demonstrates that if the central banks target the interest rate, the contraction is likely to increase the public debt ratio in many member countries. A contraction by one country unambiguously increases the debt ratio of the other. If the foreign central bank targets the money supply, the contrac tion is less likely to increase the ratio. The ratio can also be lowered with mon etary policy, and the appropriate policy is expansion in both regimes. Simula tion with an econometric model shows that, with interest rate targeting, fiscal contraction increases the debt ratios of 3 out of $14 \mathrm{EU}$ countries if the country contracts alone. If all the member countries contract simultaneously with money supply targeting by Germany, the rati os of 7 countries increase. These
\end{abstract}

\footnotetext{
*Correspondence Address: Department of Economics, FIN-33014 University of Tampere, Finland, (Tel) +358-3-364 5122, (Fax) +358-3-364 5122.

**I wish to thank the Research Institute of the Finnish Economy and Jiang-Gnang Shen for valuable help with computes stimulations in the NIGEM model.
}

(C) 2000 - Center for International E conomics, Sejong Institution. All rights reserved. 
effects persist for four to eleven quarters, whereafter the ratios begin to decline in all the countries except B elgium.

* JEL Classifications: E62, H63

- Key words: Public Debt Ratio, Fiscal Correction, M aastricht Convergence Criteria

\section{Introduction}

The $M$ aastricht convergence criteria for the Economic and $M$ onetary Union of the European Union stipulate that a member country's public debt as of the end of 1997 may be at most 60 per cent, and its public sector deficit at most 3 per cent of its GNP. As a result, member governments have cut their spending. However, as will be shown below, in a standard two-country model, fiscal contraction is likely to increase the public debt ratio in many member countries if the central banks target the interest rate. Such an effect is more likely, the greater the country's initial debt ratio and its marginal propensity to spend, and the lower its marginal propensity to import. An increase is somewhat less likely if the contraction is brought about by raising taxes or cutting transfer payments, rather than government consumption or investment, if the marginal propensity to spend is smaller than one, and somewhat more likely if it is greater than one. However, contraction by one country unambiguously increases the debt ratios of others. Both ratios can be lowered with monetary policy, and the appropriate policy is expansion in both regimes.

If the center country's central bank targets the money supply, fiscal contraction of either kind is less likely to increase the debt ratio. If the interest cost of public debt terms are dominated in the expressions, domestic fiscal contraction increases the foreign ratio, and monetary expansion lowers both the domestic and foreign ratios. In either case, it is likely to reduce the deficit ratio. Simulation with the National Institute of E conomic and Social Research quarterly econometric model shows that, with interest rate targeting, fiscal contraction increases the debt ratios of 3 out of $14 \mathrm{EU}$ countries if each country contracts alone. If all the member countries contract simultaneously with money supply targeting by Germany, the ratios of 7 countries increase. 
Recent work on the effects of fiscal contraction has relied on non-standard explanations. Giavazzi and Pagano (1990), (1995) have studied its effects via expectations, on private consumption expenditures. They suggest that life cycle income can be a declining function of $G$ as follows. A large and persistent fiscal tightening lowers the expected future tax rate, increasing the expected future disposable income. Moreover, if the central bank targets the money supply, the tightening also reduces the market interest rate, which causes negative crowding out and possibly a decline in the discount factor of expected future income, thereby increasing its present value. (It also depreciates the exchange rate, stimulating the open sector with the same results.) The wealth effect may also be strengthened by a lower probability of the government inflating away or defaulting on an unsustainable debt burden in the future. As a result, private consumption increases, which they find to be the case in Denmark after the 1983-86 fiscal reform. The same holds for Ireland in 1987-89 but not in 1982-84. The authors infer that with large and persistent changes in government consumption non-K eynesian (or rather neo-K eynesian a la M odigliani) effects may dominate, whereas with small and temporary ones the standard Keynesian effects are likely to prevail. The latter is also supported by Karras (1994), who finds, based on a sample of thirty countries, that in the aggregate, private and government consumption are best described as complementary, the strength of the relationship being negatively affected by the government's size. of course, these papers have nothing to say about the change in output, let alone the public debt ratio. (See also Bertola and Drazen (1993), and Blanchard (1990).)

Alesina and Perotti $(1995 a, b)$ argue that successful adjustments (in terms of the debt ratio) rely mostly on major cuts in transfer programs and in government wages and employment, whereas unsuccessful adjustments rely primarily on increases in taxes. They define a major adjustment as a reduction in the cyclically adjusted fiscal deficit of at least 1.5 per cent of the GNP in any given year, and explain their results with political arguments (see also Perotti (1995)). We shall return to this paper after showing our results.

In the following, the model is introduced in Section II. In Section III the regime where the central banks target the interest rate is analyzed. In Section IV, correspondingly, the case of money supply targeting by the foreign 
country is studied. In Section V, the propositions are tested by simulating the NIESR quarterly econometric model.Section VI is a brief review of earlier studies, and Section VII the conclusion.

\section{The Model}

Examine the following simple model of two countries and the rest of the world, where capital is perfectly mobile between the two countries, and the home country's central bank keeps its exchange rate at its ERM parity of one. As to the time horizon, the M aastricht agreement was concluded in 1992 , stipulating the convergence criteria as of the end of 1997, and governments got serious about the deficits a couple of years after the agreement. We are therefore interested in the intermediate-run effects of policies, and hence not in such long-run phenomena as the sustainability of the deficits (which the governments were trying to cut anyway), nor do we need to consider the intertemporal budget constraints of the private sectors. M ost EU countries (possible exceptions being Germany and the Netherlands) undertook debt reductions smaller than "major" or "large" in the sense of Giavazzi and Pagano, and Alesina and Perotti. Moreover, having reached their targets at the end of 1997, they could be expected to reconsider their policy choice with a binding constraint considerably relaxed. Thus the reductions can hardly be characterized as persistent. We are thus in the conventional Keynesian world, in which we can study the flow equilibrium effects of policies:

$$
\begin{aligned}
& d=D /(Y P) \\
& \mathrm{dF}+\mathrm{dD}=\mathrm{iD_{-1 }}+\left(\mathrm{G}-\mathrm{T}_{+}^{\mathrm{Y}} \underset{+}{)}\right) \mathrm{P} \\
& Y=E\left(Y_{+}, r\right)+G+X-M\left(\underset{+}{Y}, P_{F} / P\right) \\
& Y_{D}=Y-T(Y) \\
& F=\underset{+}{L}(\underset{+}{Y}, i) P
\end{aligned}
$$




$$
\begin{aligned}
& \mathrm{i}=\mathrm{r}+\mathrm{E}(\mathrm{P}) \\
& \dot{P}=P(Y-\bar{Y}) \\
& \left.Y_{F}=E_{F}\left(Y_{F D}, r_{F}\right)+G_{F}+X_{F}-M_{F}\left(Y_{F}, P_{F} / P\right)\right) \\
& Y_{F D}=\underset{Y_{F}-T_{F}\left(Y_{F}\right)}{+} \\
& F_{F}=\underset{L_{F}\left(Y_{F}, i_{F}\right) P_{F}}{+} \\
& i=r_{F}+\underset{E}{E}\left(\dot{P}_{F}\right) \\
& \dot{P}_{F}=P_{F}\left(Y_{F}-\bar{Y}_{F}\right) \\
& \left.X_{F}=M_{\left(Y, P_{F}\right.} / P\right) \\
& X=M_{F}\left(Y_{F}, P_{F} / P\right)
\end{aligned}
$$

In Equation (1), the public debt ratio of the home government (d) equals the public debt (D) divided by the nominal GDP (YP), where $Y$ is the real GDP and $P$ the price level. Equation (2) is the intertemporal budget constraint of the government, stating that the change in the debt, including high-powered money $F$, equals the interest expense on the public debt of the previous period, where $i$ is the nominal interest rate, plus nominal government expenditures (GP), minus its nominal tax receipts net of subsidies $(\mathrm{PT}(\mathrm{Y}))$. The $\mathrm{T}$ is a function of $\mathrm{Y}$.

Equation ( 3 ) is the equilibrium condition for the goods market, stating that $Y$ equals private expenditures $\left(E\left(Y_{D}, r\right)\right)$ plus $(G)$, plus exports $(X)$ minus imports $\left(M\left(Y, P_{F} / P\right)\right)$. The $(E)$ is a function of disposable income $Y_{D}$, and the real interest rate $r$. The $(M)$ is a function of $Y$ and the real exchange rate, where $P_{F}$ is the price level of the foreign country, with the nominal exchange rate at one. The signs below the arguments indicate the assumed signs of the partials. In Equation (4), disposable income $Y_{D}$ equals $Y$ minus net taxes ( $T$ ). Equation (5) is the money market equation, stating that the nominal money supply $(F)$ equals the nominal demand for money, the demand for real balances being a function of $Y$ and $i$. In Equation (6), the nominal interest rate equals the real interest rate plus the expected rate of 
inflation E. Equation (7) is a semi-reduced form of the supply side: the actual increase in the price level is a function of the deviation of $Y$ from its NAIRU level.

Equations (8) through (12) correspond to equations (3) through (7) for the foreign countr $y$, they have the same structure, and foreign variables are denoted by subscript $F$. Equations (13) and (14) state that the exports of either country equal its market share on the other country's import market ( or ) times the imports of the other country. Repercussions from the rest of the world are ignored. The initial price levels are set at one by an appropriate choice of units.

Our European policy experiment of the early and middle 'nineties was one of fiscal contraction under high unemployment with downward rigidity of wages and prices. In it, price level changes are not very important. In fact, in the major countries in 1992-97, the annual rate of inflation stayed within one percentage point from the mean, except for Germany, where the maximum deviation was 1.4 points (see International M onetary Fund, International Financial Statistics Yearbook). We will therefore assume that inflation expectations and actual inflation are constant at zero. Likewise, high-powered money has been a small fraction of government deficit finance so that we will ignore it. We shall examine two basic cases. In one, the interest rate is constant because the foreign central bank targets the interest rate, and in the other the foreign central bank targets the money supply.

\section{Interest Rate Targeting by the Foreign Central Bank}

The interest rate is unaffected by fiscal policy if the central bank uses it as an intermediate target. Totally differentiating Eqs. (1) through (14), and substituting the differentiated Equations (2) through (7) and (8) through (12) into the differentiated Equation (1) yields, treating ( )a n ( )as parameters for simplicity:

$$
\begin{aligned}
d d_{K}= & (1 / Y)\left\{i D_{-1}+G+d G-T_{-1}-Y d t-k_{w}(t+D / Y)\left[\left(s_{F}+m_{F}\right)\right.\right. \\
& \left.\left.\left(E_{r} d r+d G-E_{Y} Y d t\right)+m_{F}\left(E_{r F} d r_{F}+d G_{F}-E_{Y F} Y_{F} d t_{F}\right)\right]\right\},
\end{aligned}
$$

where $k_{w} \equiv 1 /\left[\left(\mathrm{s}\left(\mathrm{s}_{\mathrm{F}}+\mathrm{m}_{\mathrm{F}}\right)+\mathrm{ms}_{\mathrm{F}}\right)+(1-\quad) \mathrm{mm}_{\mathrm{F}}\right]$, or the union's national 
income multiplier. In the expression $s_{i} \equiv 1-E_{Y_{i}}\left(1-t_{i}\right)$, with $t_{i}$ the marginal tax rate, and $m_{i}$ the marginal propensity to import of country $i$. We obtain:

$$
\begin{aligned}
& \frac{d d_{K}}{d G}=\frac{1}{Y}\left[1-k_{W}\left(t+\frac{D}{Y}\right)\left(s_{F}+m_{F}\right)\right] \\
& \frac{d d_{K}}{d t}=-1+k_{W} E_{Y}\left(t+\frac{D}{Y}\right)\left(s_{F}+m_{F}\right) \\
& \frac{d d_{K}}{d r, d r_{F}}=\frac{1}{Y}\left\{D_{-1}-k_{W}\left(t+\frac{D}{Y}\right)\left[\left(s_{F}+m_{F}\right) E_{r}+m_{F} E_{r F}\right]\right\}>0 \\
& \frac{d d_{K}}{d G_{F}}=-\frac{1}{Y} k_{W} m_{F} \quad\left(t+\frac{D}{Y}\right)<0 \\
& \frac{d d_{K}}{d t_{F}}=\frac{Y_{F}}{Y} k_{W} m_{F} E_{Y F}\left(t+\frac{D}{Y}\right)>0 \\
& \frac{d d_{K}}{d G, d G_{F}}=\frac{1}{Y}\left\{1-\left(t+\frac{D}{Y}\right) k_{w}\left[s_{F}+1(+) m_{F}\right]\right\}
\end{aligned}
$$

The expressions for the contracting country's own debt ratios are composed of two components, which affect its debt ratio in opposite directions. The direct effect of e.g. government expenditures increases the fiscal deficit and the debt ratio and thus increases the ratio. However, the expenditures also increase national income, which affects the debt ratio in the opposite direction by increasing its denominator, and by reducing its numerator by the increased tax receipts. The other country's debt ratio is affected only by the part of the income effect that leaks into that country's income stream.

The derivative in Eq. (16) is positive, and a country can lower its public debt ratio by contracting its Government expenditures if the absolute value of the second term in the brackets is smaller than one. First take the special case of a small open economy with no foreign repercussions $\left(m_{F}=0\right)$. The second term reduces to $-k(\mathrm{t}+\mathrm{D} / \mathrm{Y})$, where $k \equiv 1 /(\mathrm{s}+\mathrm{m})$ is the home country's national income multiplier. This multiplier has obtained values on both sides of unity in EU countries (see NIESR (1996), and Barrell et al. (1995)).

The marginal tax rate, including employer's social security contributions 
and the value-added tax has been well over 0.5 in all the EU countries except F rance and the U.K. (see Table 1 ). In the multiplicand of the second term, $(D / Y)$ is currently above the Maastricht target of 0.6 in all the EU countries except $F$ rance, B ritain, Finland and Luxembourg, where it is 0.58 , $0.53,0.56$, and 0.07 , respectively (see Table 1 ). Therefore for a country with $D / Y$ at 0.6 or higher, the second term is likely to exceed unity if its multiplier is not much below unity. In such a case fiscal contraction increases the public debt ratio, while of course lowering the absolute debt level. The reason is that the contraction causes a decline in income. Therefore the denominator of Eq. (1) declines. The decline in income also causes a decline in tax receipts, which enter negatively in the numerator, thereby reducing the effect of $G$ on $D$. For the debt ratio not to increase, the numerator would have to decline by more than (d) times the decline in the denominator. ${ }^{1}$

When foreign repercussions are allowed, the expression in (16) declines $\left[d\left(d d_{k} / d G\right) / d m_{F}<0\right]$, increasing the probability that the contraction increases the debt ratio. The reason is that the contraction contracts imports and thus the other country's exports. This contracts the other country's income and imports, causing the home country's output to contract further, thereby raising the debt ratio. Naturally, the expressions for the foreign country are symmetrical with the ones displayed here.

Equation (17) expresses the effect of an increase in the tax rate. Its value is $Y$ times the negative of Eq. (16), except that the second term is multiplied by the marginal propensity to spend out of disposable income $E_{Y}$. This parameter has obtained values somewhat below one, but it can exceed one if the income change is expected to be permanent and the capacity utilization rate is high (see e.g. Dornbusch and Fischer (1981) and Bischoff (1971a,b)). Consequently, increases in taxes are somewhat more likely to lower the debt ratio than are government spending cuts if $E_{Y}$ is smaller than one, and somewhat less likely if $E_{Y}$ is greater than one. The reason for the discrepan-

1. However, fiscal contraction has an expansionary output effect under flexible exchange rates with perfect capital mobility if the supply of labor is a function of the nominal wage and the income elasticity of the demand for money exceeds one. See Ahtiala (1989). European labor supply typically being a function of the real wage, this is not likely to be a relevant mechanism here. 


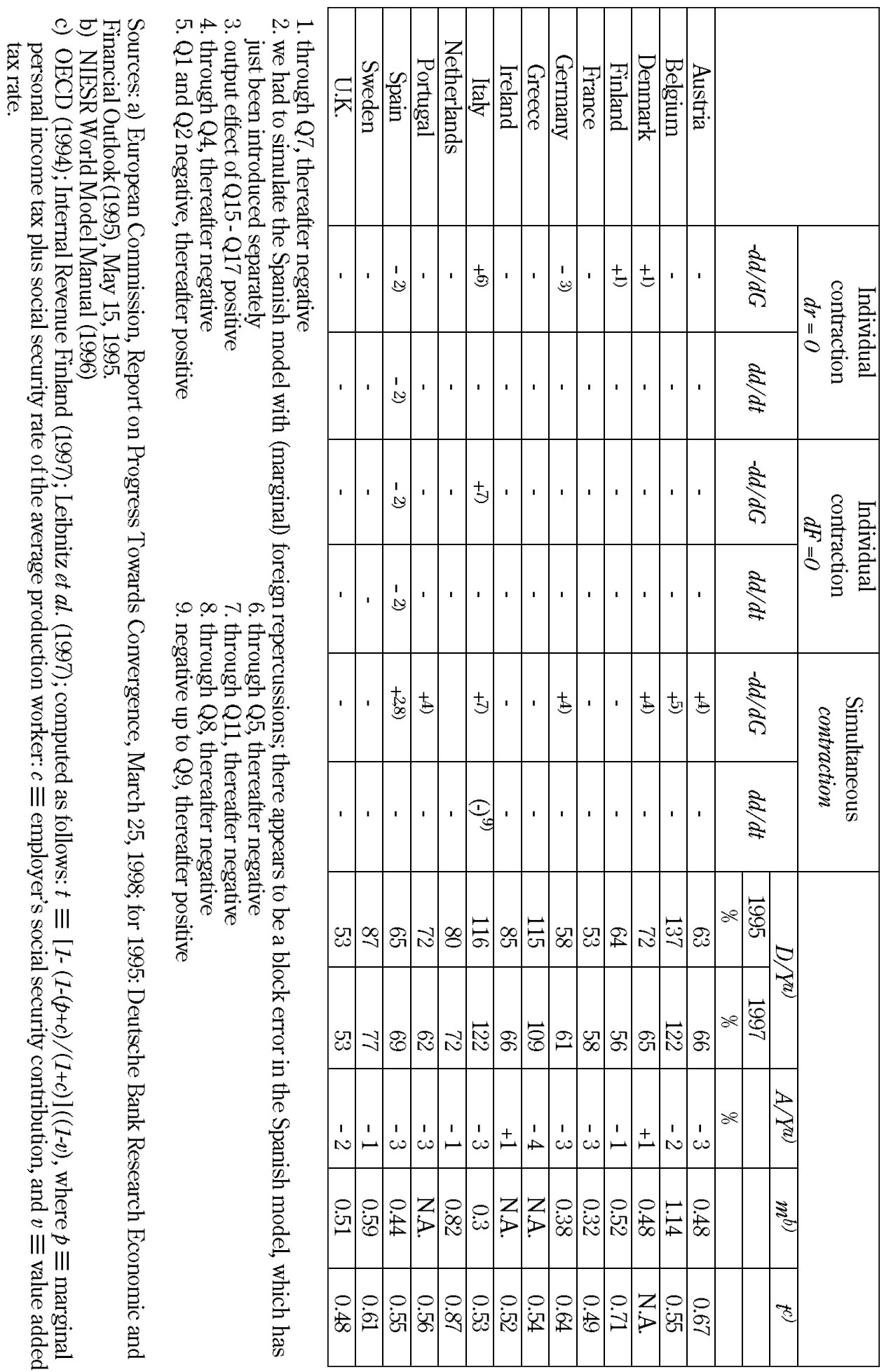


cy to Eq. (16) is of course that while government expenditures affect both total demand and the deficit dollar for dollar, the initial effect of taxes on total demand is $E_{Y}$ times the change in taxes, but dollar for dollar on the deficit.

The effect of transfer payments is $(-1 / Y)$ times the expression in Eq. (17) so that the same comments apply. The initial demand effect of transfer payments is also $E_{Y}$ times the transfer, but dollar for dollar on the deficit.

The reader can verify that the partials of $d_{k} / d G$ and $-d_{k} / d t$ with respect to $E_{Y}, D / Y, s_{F}, m_{F}$, and are negative and with respect to $m$ positive, while those with respect to $t$ are positive if $E_{Y}(1+D / Y)-1-m$ is positive. Thus for example, the greater $E_{Y}$, and $D / Y$, ceteris paribus, the more likely spending cuts are to increase the debt ratio.

Eqs. (19) and (20) express the effects of foreign government spending and taxes, respectively, on the domestic debt ratio. The former expression is negative and the latter positive. Thus foreign fiscal contraction increases the domestic debt ratio. The reason for this negative externality is of course the income and import contraction in the foreign country, which lowers the national income and tax receipts in the home country. Thus the effect of joint contraction by the home and foreign countries in Eq. (21) is more likely to increase the debt ratio than if the country contracted alone.

Finally, Equation (18) expresses the effect of monetary policy. It is positive. Thus if monetary policy were to be used to meet the $M$ aastricht criteria, the appropriate policy would be expansion. This would stimulate output and lower the interest expenses on public debt in both countries, both of which would lower the debt ratio.

It is worth noting that the expressions for the change in the fiscal deficit ratio are the same as in Eqs. (16) through (21), except that the ratio $D / Y$ is replaced by $A / Y$, where $A$ is the fiscal deficit. Thus expenditure contraction reduces the public sector deficit ratio if $k_{w}[\mathrm{~A} / \mathrm{Y}+\mathrm{t}]\left(\mathrm{s}_{\mathrm{F}}+\mathrm{m}_{\mathrm{F}}\right)<1$, a tax increase or a transfer reduction reducing it if $k_{w} E_{Y}[A / Y+t]\left(s_{F}+m_{F}\right)<1$. Since $A / Y$ has been in the single digits, the $M$ aastricht criterion being 0.03 (see Table 1), fiscal contraction is much more likely to lower the public deficit ratio than the public debt ratio. In that case, when $\mathrm{dd}_{k} / \mathrm{dG}$ is negative, fiscal contraction affects $D / Y$ and $A / Y$ in opposite directions so that both ratios cannot be lowered by fiscal policy alone. 


\section{Money Supply Targeting by the Foreign Central Bank}

$N$ ext consider the case where the foreign country is the leader and targets the money supply, while perfect capital mobility keeps the interest rates on the foreign level in both countries, the home country's central bank maintaining the exchange rate at its ERM parity. This could be dubbed a stylized simplification of the ERM world, when Germany is of course the foreign country (see Barrell et al. (1995), and M ishkin and Posen (1997)).

The change in the interest rate is obtained from Eq. (10): $(d r=) d_{F}=\left(d_{F}\right.$ $\left.-L_{Y F} d Y_{F}\right) / L_{r F}$. We obtain:

$$
\begin{aligned}
d d & =\frac{1}{Y}\left\{i_{-1} D_{-1}+G_{-1} d G+T_{-1}-Y d t+\frac{D_{-1}}{L_{F r}} d F_{F}\right. \\
& -k_{u}\left\{\left[\frac{L_{F Y}}{L_{F r}} \frac{(s+m) E_{F r}+m E_{r}}{L_{F r}} D_{-1}+\left(t+\frac{D}{Y}\right) \frac{\left(s_{F}+m_{F}\right) E_{r}+m_{F} E_{F}}{L_{F r}}\right] d F_{F}\right. \\
& +\left[\frac{L_{F Y}}{L_{F r}}(s+m) D_{-1}+\left(t+\frac{D}{Y}\right)\left(m_{F}-\frac{E_{r} L_{F Y}}{L_{F r}}\right)\right]\left(d G_{F}-E_{F Y} Y_{F} d t_{F}\right) \\
& \left.\left.+\left[\frac{L_{F Y}}{L_{F r}} m D_{-1}+\left(t+\frac{D}{Y}\right)\left(s_{F}+m_{F}+\frac{E_{F r} L_{F Y}}{L_{F r}}\right)\right]\left(d G-E_{Y} Y d t\right)\right\}\right\},
\end{aligned}
$$

where

$$
k_{u} \equiv 1 /\left\{s_{F}(s+m)+m_{F}[s+m(1-\quad)]+\left(L_{F Y} / L_{F r}\right)\left[(s+m) E_{F r}+m E_{r}\right]\right\} .
$$

We have:

$$
\begin{aligned}
& \frac{d d}{d G}=\frac{1}{Y}\left\{1-k_{u}\left[\frac{L_{F Y}}{L_{F r}} m D_{-1}+\left(t+\frac{D}{Y}\right)\left(s_{F}+m_{F}+\frac{E_{F r} L_{F Y}}{L_{F r}}\right)\right]\right\} \\
& \frac{d d}{d G}=-\frac{1}{Y} k_{u}\left[\frac{L_{F Y}}{L_{F r}}(s+m) D_{-1}+\left(t+\frac{D}{Y}\right)\left(m_{F}-\frac{E_{r} L_{F Y}}{L_{F r}}\right)\right] \\
& \frac{d d}{d G, d G_{F}}=\frac{1}{Y}\left\{1-k_{u}\left\{\frac{L_{F Y}}{L_{F r}}[s+(1+) m] D_{-1}+\left(t+\frac{D}{Y}\right)\left[s_{F}+(1+\quad) m_{F}+\right.\right.\right.
\end{aligned}
$$




$$
\begin{aligned}
&\left.\left.\left.\frac{L_{F Y}}{L_{F r}}\left(E_{F r}-E_{r}\right)\right]\right\}\right\} \\
& \frac{d d}{d F_{F}}= \frac{1}{Y L_{F r}}\left\{D_{-1}\left\{1-k_{u} \frac{L_{F Y}}{L_{F r}}\left[(s+m) E_{F r}+m E_{r}\right]\right\}\right. \\
&\left.-k_{u}\left(t+\frac{D}{Y}\right)\left[\left(s_{F}+m_{F}\right) E_{r}+m_{F} E_{F r}\right]\right\} \\
& \frac{d d_{F}}{d G}=-\frac{1}{Y_{F}} k_{u} m\left[t_{F}+\left(\frac{D}{Y}\right)_{F}+\frac{L_{F Y}}{L F_{r}} D_{F-1}\right] \\
& \frac{d d_{F}}{d G_{F}}= \frac{1}{Y_{F}}\left\{1-k_{u}(s+m)\left[t_{F}+\left(\frac{D}{Y}\right)_{F}+\frac{L_{F Y}}{L_{F r}} D_{F-1}\right]\right\} \\
& \frac{d d_{F}}{d G, d G_{F}}=\frac{1}{Y_{F}}\left\{1-k_{u}[s+(1+) m]\left[t_{F}+\left(\frac{D}{Y}\right)_{F}+\frac{L_{F Y}}{L_{F r}} D_{F-1}\right]\right\} \\
& \frac{d d_{F}}{d F_{F}}=-\frac{1}{Y_{F} L_{F r}}\left\{D_{F-1}-k_{u}\left[t_{F}+\left(\frac{D}{Y}\right)_{F}+\frac{L_{F Y}}{L_{F r}} D_{F-1}\right.\right. \\
&\left.\left.\mid(s+m) E_{F r}+m E_{r}\right]\right\}
\end{aligned}
$$

A contraction of government spending now causes the interest rate to fall, which causes two kinds of changes in the results, negative crowding out and a decline in the interest cost of government debt. The crowding-out term in the denominator of the union multiplier $k_{u}$ makes this multiplier smaller than with interest rate targeting so that the income change is smaller for a given change in total demand. This reduces the decline of the denominator of the debt ratio, and of the negative tax term in the numerator, thereby making the ratio smaller. The decline in the interest rate also directly reduces the interest cost of public debt proportionally to $D_{-1}$, which also reduces the debt ratio. Thus in general, fiscal contraction is more likely to lower the debt ratio than with interest rate targeting. Moreover, if the interest cost of public debt terms are dominated in the expressions, domes- 
tic fiscal contraction raises the foreign ratio (Eq. (27)), and monetary expansion lowers both the domestic and the foreign ratio (Eqs. (26) and (30)). The signs of the rest of the derivatives depend on the parameter values.

Since we have analyzed the different expressions in the interest rate targeting case, a sample highlighting the differences suffices here. Equation (23) expresses the effect of domestic government expenditures on its debt ratio. An increase in $\mathrm{G}$ constitutes an addition to public debt. It also increases $Y_{F}$, causing $r_{F}$ and thus $r$ to rise, which increases the interest cost of the public debt. Both these factors increase $d$. The $G$ also increases domestic income, increasing both tax receipts and the denominator of $D / Y$ directly, as well as through $Y_{F}$. The $Y_{F}$ again affects $Y$ via foreign imports and crowding out, the two effects running in opposite directions. The derivative thus has an ambiguous sign so that fiscal contraction can affect the debt ratio in either direction in the general case.

To summarize, if the countries' central banks target the interest rate, or if a country is so small relative to the "center" that its policy actions have a negligible effect on the interest rate, it is possible that fiscal contraction increases, rather than reduces its debt ratio, the more so, the larger its initial debt ratio and marginal propensity to spend, and the smaller its marginal propensity to import. The possible increase is greater with a contraction of government expenditures than with a rise in taxes or a cut in transfer programs if the marginal propensity to spend is less than one, and smaller if it is greater than one. Fiscal contraction in a country increases the debt ratio of the other country, which thus amounts to a negative externality on the country's trading partners. Thus the debt ratio is more likely to increase if all the EU countries contract simultaneously. However, monetary expansion lowers the debt ratio.

If the other country targets the money supply rather than the interest rate, the income change and the interest cost on the debt are reduced, and fiscal contraction is in general less likely to increase the debt ratio. If the interest cost terms of public debt are dominated in the expressions, domestic fiscal contraction raises the foreign debt ratio and monetary expansion lowers both the domestic and the foreign ratio. All in all, the critical variables of the EU countries are such that one would expect several countries to have increased their public debt ratio by fiscal contraction. How this prediction 
fares empirically will be discussed next.

\section{A Test}

We shall test the effects of fiscal contraction on output and the debt ratio with the National Institute Global Econometric M odel (NIGEM), which has been used in simulations for the European Commission. It is fairly elaborate, covering the large countries with large models of 60-90 equations each, with around 20 behavioral equations per country and appropriate linkages between flows and stocks and between countries (see NIESR (1996)). The models of smaller countries are smaller. In this M undell-Fleming-type quarterly model, policies have the conventional effects, e.g. fiscal contraction contracting output in the short-to-intermediate run, whereas in the long run the effect is much smaller mainly due to the interest rate and price and wage declines that the contraction causes (see B arrell et al. $(1995,1997)$ ).

We shall simulate the model for four years with 1995:Q1 as initial conditions, imposing adaptive expectations (because the model does not have static expectations as an option), and comparing the resulting changes in the public debt ratio with a control run. Two sets of tests are carried out, each consisting of a reduction in government consumption expenditures, or an increase in income taxes, by one percent of the GNP. The first set of tests is one of a small open economy: in each experiment a member country contracts fiscally in the absence of foreign repercussions. The domestic central bank - or capital flows - fixes the interest rate in one experiment ( $\mathrm{dr}=0$ in Table 1). In the other, the central bank targets the monetary base $(\mathrm{dF}=0)$.

In the second set of experiments, an "ERM economy" is studied: all the member countries contract simultaneously by one percent of the GNP in each of the two ways, their monetary authorities keeping the Deutschmark exchange rates at their ERM parities, while the Bundesbank targets the German domestic monetary base. The central banks of the outside world target the interest rate. In the Table this is called "simultaneous contraction".

As a background observation, it is worth pointing out that in practically all the cases the contraction leads to a decline in output. (The outstanding exception is Greece after the sixth quarter in simultaneous contraction, 
where output begins to increase.) The output responses are smaller when the central bank targets the monetary base rather than the interest rate, as well as with an increase in taxes rather than a contraction in government consumption, all in line with our theoretical results. In the long run, the output effect declines mainly due to the price, wage and interest rate declines caused by the contraction. These responses are not reported separately in Table 1.

The results on the debt ratio are summarized in Table 1, where a minus sign means that the debt ratio declines in response to fiscal contraction, a plus sign meaning that the debt ratio increases.

The theoretical predictions are on the whole quite well borne out by the experiments. Specifically, in general, tax increases lead to greater declines in the debt ratios than do government consumption contractions of the same size. In the light of our model, this is associated with the fact that an increase in taxes lowers income by less than an equal contraction in spending if $E_{Y}$ is smaller than one.

Increases in income taxes lead to a decline in the debt ratio in all the cases, with the partial exception of Italy in simultaneous contraction, where this response follows up to the ninth quarter, whereafter the debt ratio starts increasing.

If the central banks target the monetary base in individual contraction, a decline in government consumption and an increase in taxes lead to a decline in the debt ratio in all the cases, except I taly with a contraction in government consumption.

The most interesting cases are those in the first and third columns, since of the EU countries mainly only U.K. and Germany have been targeting their monetary bases (see M ishkin and Posen (1997)). In the first column, a decline in an individual country's government consumption leads to an increase in the debt ratio in Denmark, Finland and Italy. As proposed in connection with the analysis of Equations (16) and (17) above, a cut in government expenditures is more likely to lead to an increase in d, ceteris paribus, in countries with a high $D / Y$ and $E_{Y}$, and a low $m$. It is easy to see why the high-debt Italy and Denmark are in this category. However, the high-debt Belgium and the Netherlands have a negative $-\mathrm{dd}_{\mathrm{k}} / \mathrm{dG}$. This is at least partly associated with the fact that these countries have a high $\mathrm{m}$. (The values of 
these parameters are displayed in the Table for easy reference.)

The $d$ remains on a higher level for only 5-7 quarters. Thereafter, the effects of the price decline begin to dominate: it stimulates the economy through real exchange rate depreciation and the wealth effect, which also begins to lower the debt ratio. This standard property of macro models can be expected to hold under "normal" conditions starting from equilibrium. The initial conditions in the mid-nineties were a period of very low inflation and high unemployment in E urope - hardly a long run equilibrium. The former makes one rather skeptical about the downward flexibility of prices, which would require price declines, rather than slowdowns of price increases, in many cases. The latter condition arouses doubts about the upward flexibility, which can be expected to be greater than the downward flexibility, however. If this conjecture is correct, one would expect the effects on the debt ratio to persist longer than the model predicts.

In simultaneous contraction, the debt ratio increases also in Austria, Belgium, Germany, Portugal, and Spain in addition to Denmark and Italy, or in half of the countries. Thus for the new countries, Eq. (16), without foreign repercussions ( $m_{F}=0$ ), is positive and $E q$. (25) negative. A necessary condition for this is: $m_{F}>\left(L_{F Y} / L_{F r}\right)\left[E_{r}-(s+m) D_{-1} /(t+D / Y)\right]$. Thus, in contracting, a country imposes a negative externality on its trading partners through imports, which lowers their outputs and raises their debt ratios (left hand side of the inequality). In the presence of German monetary base targeting, this effect is partly counteracted by negative crowding out and by the interest cost on the debt due to a decline in the interest rate (right hand side above). The smaller the country, the smaller its market share ( on its union partners' markets), and the more likely the crowding out and interest cost terms are to dominate, hence making Eq. (25) larger than Eq. (16).

Denmark's debt ratio increases more and longer with a fixed interest rate than with joint contraction so that the reverse inequality holds, although both derivatives are negative. Denmark's output declines quickly to stay on roughly the same lower level in the fixed interest rate case, whereas in the joint contraction case it initially declines by more, to rise slowly thereafter. The income changes are roughly equal in the two cases during the thirteenth quarter.

A more extreme case is Finland, whose debt ratio declines in simultane- 
ous contraction, while increasing in individual contraction. Thus the reverse inequality holds and the interest cost and crowding out terms appear to dominate the import effect $\left(m_{F}\right)$ from other countries in Eq. (25). Indeed, during the period during which the NIGEM model was estimated the correlation coefficient of Finland's industrial output with those of Germany and France were -0.09 , and 0.36 , respectively. The former is not statistically significantly different from zero, however (see Sverige och EMU, Table 5.2). This appears to be associated with the large share of Soviet trade up till the late eighties, whose fluctuations were often politically motivated.

The positive effects on the debt ratio of Austria, Denmark, Germany, and Portugal last for only a year, whereas those of Belgium, Italy, and Spain last for eight quarters or more. If the reservations expressed above about the price effects are correct, the positive effects can be expected to last longer. Then these countries would do well to try to persuade the other member countries to expand in concert instead of contraction.

\section{Earlier Studies}

Of earlier studies, Giavazzi and Pagano $(1990,1995)$ study private consumption expenditures. Since most fiscal corrections in response to the $M$ aastricht treaty have been relatively small, one would expect the standard results to hold most of the time, and private consumption to decline in response to a cut in government consumption, as suggested in the Introduction. As to the Alesina - Perotti (1995a, b) hypothesis, this skillfully and imaginatively executed study is in agreement with our result in that taxes sometimes have a weaker effect on the debt ratio than do government consumption expenditures, whereas we find that transfer payments also have a weaker effect whenever taxes do. While theoretically plausible, the latter studies ignore both the monetary policy regime and all the other changes in the economy caused by the contraction. Not only are government expenditures and tax receipts a function of income (as pointed out by Giavazzi in his discussion of the paper), but income is also a function of taxes, government expenditures and other variables. Therefore the Alesina - Perotti observation that fiscal correction is likely to be more successful if the economy is growing rapidly (i.e. $\mathrm{E}$ or $\mathrm{X}$ is rising) may be a more important explanation 
for the success of the correction than are compositional factors. Likewise, fiscal correction may be part of a change in the policy mix, the other part being monetary relaxation. Finally, fiscal reform may be accompanied by devaluation or depreciation, which also increases $X$ and lowers $M$, lowering the debt ratio, as can be verified by straightforward steps. This appears to be at least part of the explanation for the $D$ anish experience.

\section{Concluding Comments}

We have developed a simple two-country model of the effects of fiscal contraction on the public debt ratio. It was shown that the direction of the effect of fiscal contraction on the public debt ratio depends on the countries' macroeconomic structure and monetary policy regime. If central banks target the interest rate, fiscal contraction is likely to increase, rather than lower, the ratio in several EU member countries. Then the appropriate fiscal policy for lowering the debt ratio would be expansion. An increase in the ratio is somewhat less likely if the contraction is brought about by an increase in taxes or a decrease in transfer payments rather than by government consumption or investment, if the marginal propensity to spend is less than unity, and somewhat more likely if it is more than unity. However, contraction by a country unambiguously increases the debt ratios of others.

Contraction is less likely to increase the debt ratio if the "center country's" central bank targets the money supply, unless the countries contract together. However, contraction is likely to lower the deficit ratio in both regimes. $M$ onetary policy can also be used to lower these ratios, and the appropriate policy is expansion in the interest rate targeting case. The same holds in the case of monetary base targeting if the interest cost terms of public debt are dominated in the expressions.

Simulation of the econometric model of the National Institute of Economic and Social Research suggests that with interest rate targeting, contraction increases the debt ratios of 3 out of 14 countries when each country contracts alone without foreign repercussions. If all the member countries contract simultaneously with money supply targeting by Germany, the ratios of 7 countries increase. However, these effects persist for four to eleven quarters, whereafter the ratios begin to decrease in all the countries except B el- 
gium, due to the price and wage declines of the model. We expressed reservations about the relevance of the price-wage mechanism for the $E U$ in the early-to-mid nineties, however. If this conjecture is correct, the policy effects can be expected to last longer.

It is seen that several EU countries have pursued the M aastricht public debt criterion with a policy that not only has been costly in terms of lost output and employment but has moved the countries away from the debt target. In so doing, the countries have also imposed a negative externality on each other by causing their imports from their EU partners to decline, which has increased the partners' debt and deficit ratios. Yet they would have had a much less costly instrument available in coordinated monetary expansion, which would have helped solve both the unemployment and the debt problems. ${ }^{2}$

Why then have the debt ratios of several EU countries recently been declining in spite of often counterproductive fiscal policies? In the light of this paper's results the answer is indeed easier national monetary policies, which became possible thanks to the collapse of the Exchange Rate M echanism in 1992. This freed central banks from defending the exchange rate parities, and thereby from following tight Bundesbank policy after the supply shock from German unification, which pushed the German money market rate to 9.4 per cent in 1992 (see IM F (1996a)). The subsequent relaxation by the Bundesbank lowered the money market rate to 3.3 per cent at the end of 1996 and made further relaxation possible, member countries transmitting positive growth impulses to each other through imports.

2. The $M$ aastricht agreement assigns the $n$ member countries the task of achieving $n$ fiscal deficits and $n-1$ exchange rates in addition to the requirements on the inflation rate and the long-term interest rate relative to to the mean of the best three countries, which normally calls for more than the $2 n$ instruments of fiscal and monetary policies. Accordingly, countries have used gimmicks of creative accounting and labor market reforms. Naturally, they still find their conventional targets important. 


\section{References}

Ahtiala, Pekka (1989), “A Note on Fiscal Policy Under Flexible Exchange Rates," European E conomic Review ; 1481-1486.

Alesina, Alberto, and Roberto Perotti (1995(a)), "Fiscal Expansions and Adjustments in OECD Countries," E conomic Policy ; 207-248.

Alesina, Alberto, and Roberto Perotti (1995b), "Reducing Budget Deficits", Unpublished M anuscript, Harvard University.

Barrell, Ray, Julian Morgan, and Nigel Pain (1995), "The Employment

Effects of the M aastricht Fiscal Criteria", Report Prepared for the Temporary Committee on Employment of the European Parliament, National Institute of Economic and Social Research, London.

Barrell, Ray, and James Sefton (1997), "F iscal Policy and the M aastricht Solvency Criteria," The M anchester School LXV, (3); 259-279.

Bertola, Giuseppe, and Alan Drazen (1993), "Trigger Points and Budget Cuts: Explaining the Effects of Fiscal Austerity," American E conomic Review, 83:1; 11-26.

Bischoff, Charles W (1971a), "The Effects of Alternative Lag Distributions," in G. Fromm (ed.), Tax Incentives and Capital Spending, Washington D.C.: The Brookings Institution.

Bischoff, Charles W (1971b), "Business Investment in the 1970's: A Comparison of M odels," Brookings Papers on E conomics Activity 1.

Blanchard, Olivier (1990), "Comments on Giavazzi and Pagano," in Olivier Blanchard and Stanley Fischer, (eds.), NBER M acroeconomics Annual, Cambridge, M A: MIT Press; 110-117.

Dornbusch, Rudiger, and Stanley Fischer (1981),M acroeconomics, Second Edition, New York: M cGraw-Hill .

Giavazzi, Francesco, and M arco Pagano (1990), “Can Severe Fiscal Adjustments be Expansionary," NBER Macroeconomics Annual, Cambridge, M A: M IT Press; 75-116.

Giavazzi, Francesco, and M arco Pagano (1995), “Non-Keynesian Effects of Fiscal Policy Changes: International Evidence and the Swedish Experience," NBER Working Paper 5332.

Karras, Georgios (1994), "Government Spending and Private Consumption: Some International Evidence," Journal of M oney, Credit, and Banking, 
26(1); 9-22.

Leibnitz, Willi, John Thornton, and Alexandra Bibbee (1997), “Taxation and Economic Performance," OECD Economics Department Working Paper No. 196, Paris .

Mishkin, Frederic, and Adam Posen (1997), "Inflation Targeting: Lessons from Four Countries," Federal Reserve Bank of New York E conomic Policy Review.

Perotti,Roberto (1996), "Fiscal Consolidation in Europe: Composition M atters," American Economic Review, 86,(2); 105-110.

The Commission of the European Communities [1997], The Single M arket Review Series, Brussels.

International M onetary Fund (1996a), International Financial Statistics Yearbook, Washington, D.C..

International M onetary Fund (1996b), World Economic Outlook, Washington, D.C.

The World M odel Manual (1996), National Institute of E conomic and Social Reserach, London.

OECD[1994], Taxation and Household Saving, Paris.

Sverige och EMU (Sweden and EMU) (1996), betankande av EMUutredningen, Stockholm: Statens offentliga utredningar ; 158. 